\title{
Musculoskeletal disorders among dentists and dental students in West Sumatera, Indonesia
}

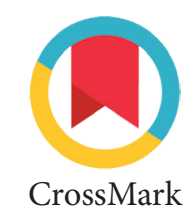

Abu Bakar, ${ }^{1,2}$ Rifani, ${ }^{1}$ Valendriyani Ningrum ${ }^{3 *}$, Shih C. Lee ${ }^{2}$

\section{Abstract}

Objective: The purpose of this study is to describe the prevalence of musculoskeletal disorders (MSDs) in dentist and dental students in West Sumatera.

Material and Methods: The study design was cross-sectional with 261 samples by using total sampling technique. The instrument was Nordic Body Map (NBM) questionnaire and Cornell Musculoskeletal Discomfort Questionnaires (CMDQ).
Results: Some anatomical body parts were indicated to have a high prevalence in experiencing musculoskeletal disorders. They were waist (55\%), right shoulder (49\%), upper neck (48\%), right wrist $(45 \%)$, and lower neck (42\%), respectively. The quality of the pain was varied.

Conclusion: The high prevalence of MSDs may cause by static postures and the big force needed by certain body parts during the dental treatment.
${ }^{1}$ Department of Oral Medicine, Faculty of Dentistry, Universitas Baiturrahmah, Padang, Indonesia ${ }^{2}$ Department of Food Science and Biotechnology, Dayeh University, Changhua, Taiwan

${ }^{3}$ Department of Pediatric Dentistry, Faculty of Dentistry, Universitas Baiturrahmah, Padang, Indonesia

*Correspondence to: Valendriyani Ningrum, Department of Pediatric Dentistry, Faculty of Dentistry, Universitas Baiturrahmah, Padang, Indonesia

valend888@gmail.com

Received: 27 December 2018 Revised: 20 February 2019 Accepted: 5 March 2019 Available Online 1 August 2019

Keywords: Body parts, Musculoskeletal Disorders, NBM

Cite this Article: Bakar A, Rifani, Ningrum V, Lee SC. 2019. Musculoskeletal disorders among dentists and dental students in West Sumatera, Indonesia. Journal of Dentomaxillofacial Science. 4(2): 92-95. D01:10.15562/jdmfs.v4i2.921

\section{Introduction}

Musculoskeletal Disorders (MSDs) complaints that occur among dentists have increased over the last decade and become a very significant issue in the world of health. Dental practitioners can spend a lot of time statically in a rigid and non-ergonomic position while doing the repetitive movement with heavy loads. Job factors in the profession are the main risk of MSDs complaints. ${ }^{1}$

Numerous studies had reported high prevalence of MSDs in dentists and dental students..$^{2-17}$

The prevalence of MSDs in the neck and shoulders was $65 \%$ and $59 \%$ in the lower back. $^{2}$ A study conducted in Karachi, Pakistan showed the main clinical symptoms of MSDs in doctors are often felt in the neck area (96\%), shoulders (90\%) and upper extremities (82\%). Almost the same pain is felt in the lower limb area $(46 \%)$ and thigh/hip area (4s4\%). Pain is also felt in the knee (34\%) and ankle/foot $(20 \%) .^{3}$ A systematic review that was carried out in Iran in 2017 resulted that the prevalence of MSDs occurs between $0.5 \%$ and $70 \%$. The prevalence of MSD varies including neck pain (0.7-0.15), back pain (0.08-0.55), wrist pain $(0.005-0.48)$, shoulder pain (0.08-0.5), knee pain (0.03 to 0.25$)$ and elbow pain (0.01 to 0.2$).^{4}$ Meanwhile, in China, this complaint occurred in $88 \%$ of dentists, who had at least one complaint in the limbs and the highest complaint $83.8 \%$ occurred in the neck. ${ }^{10}$ Hayes et al. $^{7}$ the same conclusion that MSD complaints were highest in dental hygienist students in Australia in the neck
(57.94\%) and shoulder (48.41\%). ${ }^{11}$ Research in Iran conducted by Tirgar et al. ${ }^{16} 83.3 \%$ of dentists had the highest complaints of neck pain, $56.7 \%$ complained about back pain and $41 \%$ of shoulder problems. ${ }^{16}$ A literature review was conducted to analyze the relation of MSDs in general dentist and orthodontic work. The study showed that the number of published studies reporting MSDs in dentists and the investigations that carried out were still relatively small. ${ }^{5}$

The review conducted by Burdorf and Sorock estimated the three categories of risk factors in Musculoskeletal Disorder (MSD), there are physical, psychological and individual characteristics. Physical factors are classified as handling materials manually, the frequency of bending and twisting, heavy physical loads, static work postures, repetitive movements, and vibrations throughout the body. Psychological factors consist of mental stress, job dissatisfaction, work speed, low job support, and latitude of low work decisions or monotonous work. And individual characteristics that are age, gender, height, weight, smoking, sports, marital status, and education..$^{18}$

Apart from these facts, the prevalence of MSD in dentists and dental students in Indonesia, especially in the West Sumatra region is still hardly known. Therefore, our study aimed to determine the prevalence of MSD among dentists and dental students in West Sumatra.

\section{Material and Methods}

This research is an observational surver study with cross-sectional design. The samples were 
dentists and dental students in West Sumatra. Research subjects must have experienced dental practice for at least 6 months and no prior history of MSDs. Informed consent was given to the respondent before the questionnaire was provided. Ethical permission was obtained from the Research Ethics Committee of the Faculty of Medicine, Andalas University, Indonesia (628/KEP/FK/2018).

Nordic Body Map (NBM) instrument used in this study to obtain the data of MSDs complaints in respondents. And Cornell Musculoskeletal Discomfort Questionnaires (CMDQ) developed by Dr Alan Hedge on student ergonomics at Cornell University used as the second instrument to assess the complaints felt by respondents which emerged because of their work load. MSDs is characterized by pain, heat, cramps, numbness, swelling and stiffness. The CMDQ originated from a previous survey that conducted to assess the inconvenience of job posture. This survey is a screening tool and not a diagnostic instrument. The CMDQ describes the working frequency in a week, the severity of work and the effect of disruption to the ability to work on musculoskeletal discomfort in 20 parts of the body.

Cornell Musculoskeletal Discomfort Questionnaires (CMDQ) is used to assess subjective complaints felt by respondents arising from their work. MSD complaints are characterized by pain, heat, cramping, feeling dead, swollen, stiff, and stiff. In this study, the questionnaire was validated using SPSS. Cronbach alpha obtained was 0.857 (indicating high internal reliability of the questionnaire). The total correlation of the corrected items varied from 0.262-0.507 and there was no change if one item.

Data were processed and analyzed by using Ms. excel where the obtained data was converted into tables and charts. From the illustration, we classified the complaints from the respondents in each part of the body (mild pain, moderate pain and severe pain). The prevalence was calculated based on the percentage of the complaints from the number of collected respondents.

\section{Table 1 Individual characteristic}

\begin{tabular}{llll}
\hline Characteristic & Average & Minimum & Maximum \\
\hline Age & 28 years old & 22 years old & 61 years old \\
Height & $158 \mathrm{~cm}$ & $140 \mathrm{~cm}$ & $172 \mathrm{~cm}$ \\
Weight & $58 \mathrm{~kg}$ & $38 \mathrm{~kg}$ & $96 \mathrm{~kg}$ \\
Sleep Duration & Number $(\mathrm{N})$ & Percentage $(\%)$ & \\
<6 jam & 93 & 35.6 & \\
6-8 jam & 105 & 40.2 & \\
$>8$ jam & 64 & 24.5 & \\
\hline
\end{tabular}

\section{Results}

This study was conducted in West Sumatra, Indonesia. Table 1 reveals the individual characteristics that consist of the minimum, maximum and average age, height, weight from each respondent that participate in this study. Data on sleep duration characteristics were also obtained based on the number of respondents.

The data obtained shows the prevalence of MSD complaints in several body parts in percentage figure 1 . The complaints were classified into severe, moderate and mild pain indicating the severity of MSD complaints felt by patients.

\section{Discussion}

The study conducted by Ehsan et al. ${ }^{19}$ showed the most frequent complaints of MSD in the neck, shoulders, upper back, lower back and wrists. ${ }^{11}$ Research by Decharat et al. 12 state that MSD complaints in dentists in Southern Thailand were highest in the shoulder (86.4\%), neck (67.8\%), lower back $(47.0 \%)$ and hands/wrists (7.58\%). ${ }^{12}$ MSD in India occurs in more than a third of dentists and occurs most often in the neck (52\%), lower back (41\%), shoulder (29\%) and wrist (26\%). ${ }^{13}$ MSD prevalance in Saudi Arabia is also high at $85 \%$ of dentists, the complaints area includes the lower back, shoulder, neck hands, upper back and other areas such as elbows, buttocks, thigh and legs. ${ }^{14} \mathrm{MSD}$ occurs in $95.7 \%$ of dentists the neck, shoulders, back, wrists and knees. ${ }^{15 \mathbb{D}}$ Morse study found same results, namely the highest MSD complaints on the back, then neck and shoulders in the scope of dental work that occured conservatively 1 of 4 dental professionals both dentists, dental, students, dental nurses and dental hygienists. ${ }^{17}$ The results of the current study supported the majority of MSD complaints in the previous study, even though in same order. The result showed that five major MSD complaints in dentists and dental students in West Sumatra were waist, right shoulder, upper neck, right wrist and lower neck. Job postures that performed by dentists, sitting or standing can cause problems in the back, neck and shoulders. the same thing happens to the feet that form blood clots due to the loss of appropriate control.

The profession as a dentist is assumed to have a static, repetitive, rigid movements and need more than $50 \%$ of the muscle to contract. The arm and wrist are also parts of the body that often require to 


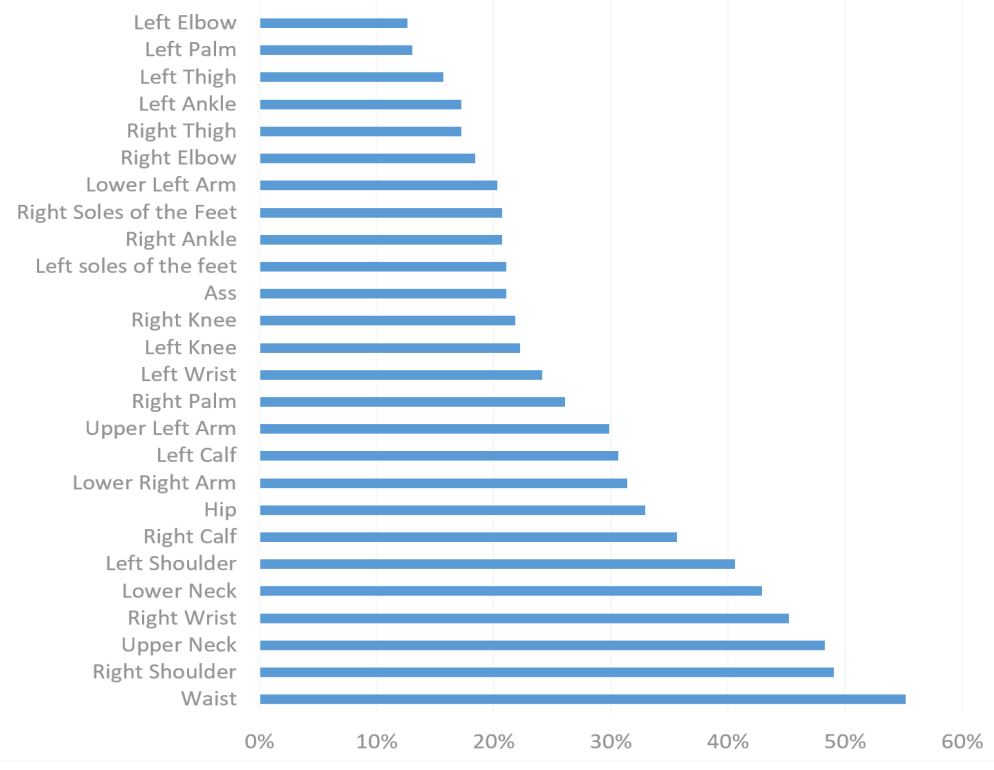

Figure 1 MSD prevalence based on anatomical body part

Table 2 MSD complaints based on the severity of pain

\begin{tabular}{|c|c|c|c|c|c|c|}
\hline \multirow[t]{2}{*}{ MSD Complaints (body parts) } & \multicolumn{2}{|c|}{ Mild Pain } & \multicolumn{2}{|c|}{ Moderate Pain } & \multicolumn{2}{|c|}{ Severe Pain } \\
\hline & $\mathbf{F}$ & $\%$ & $\mathbf{F}$ & $\%$ & $\mathbf{F}$ & $\%$ \\
\hline Waist & 105 & 40 & 34 & 13 & 5 & 2 \\
\hline Right Shoulder & 77 & 30 & 50 & 19 & 1 & 0 \\
\hline Upper Neck & 96 & 37 & 29 & 11 & 1 & 0 \\
\hline Right Wrist & 100 & 38 & 14 & 5 & 4 & 2 \\
\hline Lower Neck & 89 & 34 & 20 & 8 & 3 & 1 \\
\hline Left Shoulder & 87 & 33 & 15 & 6 & 4 & 2 \\
\hline Right Calf & 77 & 30 & 13 & 5 & 3 & 1 \\
\hline Hip & 58 & 22 & 18 & 7 & 10 & 4 \\
\hline Lower Right Arm & 55 & 21 & 20 & 8 & 7 & 3 \\
\hline Left Calf & 67 & 26 & 11 & 4 & 2 & 1 \\
\hline Upper Left Arm & 64 & 25 & 11 & 4 & 3 & 1 \\
\hline Right Palm & 58 & 22 & 7 & 3 & 3 & 1 \\
\hline Left Wrist & 55 & 21 & 5 & 2 & 3 & 1 \\
\hline Left Knee & 49 & 19 & 2 & 1 & 7 & 3 \\
\hline Right Knee & 49 & 19 & 5 & 2 & 3 & 1 \\
\hline Ass & 43 & 16 & 3 & 1 & 9 & 3 \\
\hline Left Sole of The Feet & 45 & 17 & 6 & 2 & 4 & 2 \\
\hline Right Ankle & 49 & 19 & 4 & 2 & 1 & 0 \\
\hline Right Sole of The Feet & 48 & 18 & 6 & 2 & 0 & 0 \\
\hline Lower Left Arm & 36 & 14 & 9 & 3 & 8 & 3 \\
\hline Right Elbow & 34 & 13 & 3 & 1 & 11 & 4 \\
\hline Right Thigh & 33 & 13 & 6 & 2 & 6 & 2 \\
\hline Left Ankle & 35 & 13 & 5 & 2 & 5 & 2 \\
\hline Left Thigh & 30 & 11 & 4 & 2 & 7 & 3 \\
\hline Left & 27 & 10 & 3 & 1 & 4 & 2 \\
\hline Left Palm & 25 & 10 & 1 & 0 & 7 & 3 \\
\hline
\end{tabular}

The profession as a dentist is assumed to have a static, repetitive, rigid movements and need more than $50 \%$ of the muscle to contract. The arm and wrist are also parts of the body that often require to produce big power during dental treatment such as tooth extraction, scaling and minor surgery. Dentists and dental students also need static postures and legs as support both when standing and or sitting. Static posture is one of the main factors in the occurrence of MSD complaints.

MSD complaints data based on severity indicate that the percentage range is still dominated by mild pain complaints (10-40\%), while moderate and severe pain have relatively small percentages and prevalence (0-19\% complaints and very sick $0-4 \%$ ). The subjectivity of respondents can influence the level of pain felt by respondents. Bhornsawan et al. ${ }^{208}$ proposed Bayesian Network (BN) which describes a meaningful relationship between multiple variables on MSD complaints caused by work. The structure of the $\mathrm{BN}$ model is grouped into enabling conditions, faults and consequences. Enabling conditions consist of individual factors, work, stress and posture. ${ }^{12}$ This study confirms the differences in the level of pain between individuals and the diverse distribution associated with MSD complaints. The severity of pain and the pain level above $10 \%$ is still dominated by the neck, shoulders and back. This shows the consistency of the results with previous studies that mention posture (neck, back and shoulders) are the body parts that at risk the most for the occurrence of MSD complaints. ${ }^{13-15,21,22}$

Several studies analyzed the length of work, operator position and psychological effects of various static postures. Other studies analyze the relationship between muscle contraction and muscle imbalance, which is related to the development of pain and MSD. Static adherence can cause muscle fatigue and imbalances that produce muscle ischemia or necrosis. Pain occurs after the process. Muscle protection is released during pain and results in joint hypomobility, nerve compression and spinal disk degeneration. MSD is a result of the inability of joint mobility and nerve compression. ${ }^{5,23,24}$

The differences in the results of this study with previous research can occur due to several conditions. Respondents may not feel or be not aware of the conditions associated with MSD. The implementation of the research method with the cross-sectional method has limitations in seeing the process and memory of respondents who are limited to time. Based on the results of the study, ergonomic interventions and physical activity may 
have a good impact on preventing MSD..$^{20,25-28}$

\section{Conclusion}

The prevalence of MSD complaints in dentists and dental students in West Sumatra is quite high with a distribution that varies based on the body part and the severity. Waist, right shoulder, upper neck, right wrist and lower neck are parts of the body that most frequently complained by respondents. The severity of each body parts are also different and generally, MSD complaints are dominated by mild pain. The high prevalence of MSD is due to the presence of static posture and the great pressure needed by some parts of the body during dental treatment. Further research is needed to identify appropriate preventive interventions to prevent the occurrence of MSD.

\section{Acknowledgment}

Special thanks to PDGI (Persatuan Dokter Gigi Indonesia) West Sumatera and Academic Dental Hospital Baiturrahmah University.

\section{Conflict of Interest}

The authors report no conflict of interest.

\section{References}

1. Pedro CBA, Ivisson CMS, Lais MGS, et al. Musculoskeletal disorders among brazilian dentists. Arch Environ Occup Health 2011;66: 231-235.

2. Finsen L, Christensen H, Bakke M. Musculoskeletal disorders among dentists and variation in dental work. Appl Ergon 1998;29: 119-125.

3. Sannam KR, Ahmad F, Merchant MS. Prevalence of work-related musculoskeletal disorders (MSD) among dentists. Int J Contemp Med Res 2017;4: 1208-1211.

4. Narges SSH, Tahereh V, Zeinab M, et al. Prevalence of musculoskeletal disorders among dentists in iran: a systematic review. Mater Sociomed 2017;29: 257-262.

5. Sakzewski L, Naser-ud-Din S. Work-related musculoskeletal disorders in dentists and orthodontists: A review of the literature. Work 2014: 37-45

6. Pargali N, Jowkar N. Prevalence of musculoskeletal pain among dentists in Shiraz, Southern Iran. IJOEM 2010;1: 69-74.

7. Hayes MJ, Smith DR, Taylor JA. Musculoskeletal disorders and symptom severity among Australian dental hygienists. BMC Res Notes 2013;6: 1-5.

8. Piyapat D, Teerada P, Sirichai K, et al. Prevalence and associated factors of musculoskeletal pain among the dental personnel in a Dental School. J Med Assoc Thai 2010;93: 1-6.

9. Forouzan R, Azadeh Z, Arash S, et al. Prevalence of Upper Extremity Musculoskeletal Disorders in Dentists: Symptoms and Risk Factors. J Environ Public Health 2015: 1-6.
10. Feng $B$, Liang $Q$, Wang $Y$, et al. Prevalence of workrelated musculoskeletal symptoms of the neck and upper extremity among dentists in China. BMJ Open 2014;4: 1-8.

11. Hayes M, Smith D, Cockrell, D. Prevalence and correlates of musculoskeletal disorders among Austral an dental hygiene students. Int J Dent Hyg 2009;7: 176-181.

12. Decharat S, Phethuayluk P, Maneelok S. Prevalence of musculoskeletal symptoms among dental health workers, Southern Thailand. Adv Prev Med 2016: 1-6.

13. Muralidharan D, Fareed N, Shanthi M. Musculoskeletal Disorders among Dental Practitioners: Does It Affect Practice?. Epidemiol Res Int 2013: 1-6.

14. Alghadir, A, Zafar H, Iqbal ZA. Work-related musculoskeletal disorders among dental professionals in Saudi Arabia. J Phys Ther Sci 2015;27: 1107-1112.

15. Mansoor SN, Yousaf O, Rathore FA, et al. Frequency of musculoskeletal disorders among dental professionals at armed forces institute of dentistry. JPDA 2013;22: 185-188.

16. Tirgar A, Javanshir K, Talebian A, et al. Musculoskeletal disorders among a group of Iranian general dental practitioners. J Back and Musculoskelet 2015;28: 755-759.

17. Morse, Bruney H, Dussentschleger J. Musculoskeletal disorders of the neck and shoulder in the dental professions. Work 2010;35: 419-429.

18. Burdorf A, Sorock G. Positive and negative evidence of risk factors for back disorders. Scand J Work Environ Health 1997;23: 243-256.

19. Ehsan R, Zahra J, Farzad OK, et al. A study on job postures and musculoskeletal illnesses in dentists. Int J Occup Med Environ Health 2013;26: 615-620.

20. Bhornsawan T, Siriwan S, Yupin S, et al. A system for predicting and preventing work-related musculoskeletal disorders among dentists. Comput Methods Biomec Biomed Eng 2014;17: 177-185.

21. Leggat PA, Smith DR. Musculoskeletal disorders selfreported by dentists in Queensland, Australia. Aust Dent J 2006;51: 324-327.

22. Rising DW, Bennett BC, Hursh K. Reports of body pain in a dental student population. J Am Dent Assoc 2005;136: 81-86.

23. Khan SA, Chen KY. Effect of working characteristics and taught ergonomics on the prevalence of musculoskeletal disorders amongst dental students. BMC Musculoskelet Disorders 2013;14: 1-8.

24. Valachi MS, Valachi K. Mechanisms leading to musculoskeletal disorders in dentistry. JADA 2003;134: 1344-1350.

25. Sharma P, Golchha V. Awareness among Indian dentist regarding the role of physical activity in prevention of work related musculoskeletal disorders. Indian J Dent Res 2011;22: 381-384

26. Tunwattanapong P, Kongkasuwan R, Kuptniratsaikul V. The effectiveness of a neck and shoulder stretching exercise program among office workers with neck pain: a randomized controlled trial. Clin Rehab 2015;30: 64-72.

27. Sihawong R, Janwantanakul P, Jiamjarasrangsi W. Effects of an exercise programme on preventing neck pain among office workers: a 12-month cluster-randomised controlled trial. Occup Environ Med 2013;71: 63-70.

28. Andersen LL, Zebis, MK. Process Evaluation of workplace interventions with physical exercise to reduce musculoskeletal disorders. Int J Rheumatol 2014: 1-11.

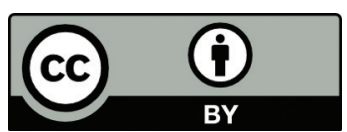

This work is licensed under a Creative Commons Attribution 